Supporting Information

\title{
Carbon Deposition on Heterogeneous Pt Catalysts Promotes the Selective Hydrogenation of Halogenated Nitroaromatics
}

Kaijia Li,,${ }^{1+}$ Ruixuan Qin, ${ }^{1 *}$ Kunlong Liu, ${ }^{1 *}$ Wenting Zhou, ${ }^{1}$ Ning Liu, ${ }^{1}$ Yazhou Zhang, ${ }^{1}$ Shengjie Liu, ${ }^{1}$ Jie Chen, ${ }^{1}$ Gang $F u,{ }^{1}$ and Nanfeng Zheng ${ }^{1 *}$

${ }^{1}$ State Key Laboratory for Physical Chemistry of Solid Surfaces, Collaborative Innovation Center of Chemistry for Energy Materials, and National \& Local Joint Engineering Research Center for Preparation Technology of Nanomaterials, College of Chemistry and Chemical Engineering, Xiamen University, Xiamen 361005, China

₹ These authors contributed equally.

* Corresponding authors: nfzheng@xmu.edu.cn (N. F. Zheng) 

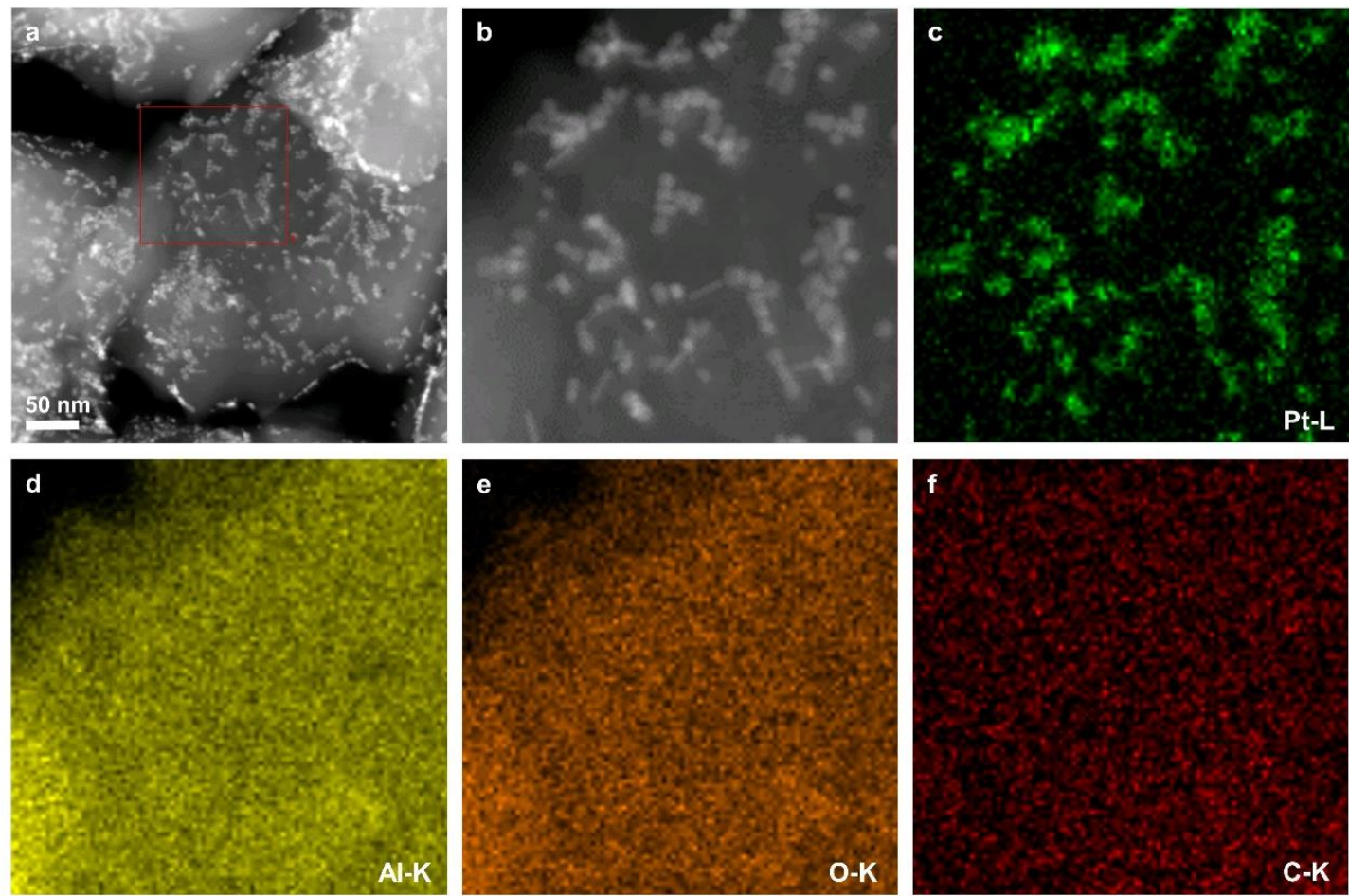

Figure S1 HAADF-STEM-EDX mapping images of Pt NPs@ $\mathrm{PtC}_{\mathrm{x}} / \gamma-\mathrm{Al}_{2} \mathrm{O}_{3}$.

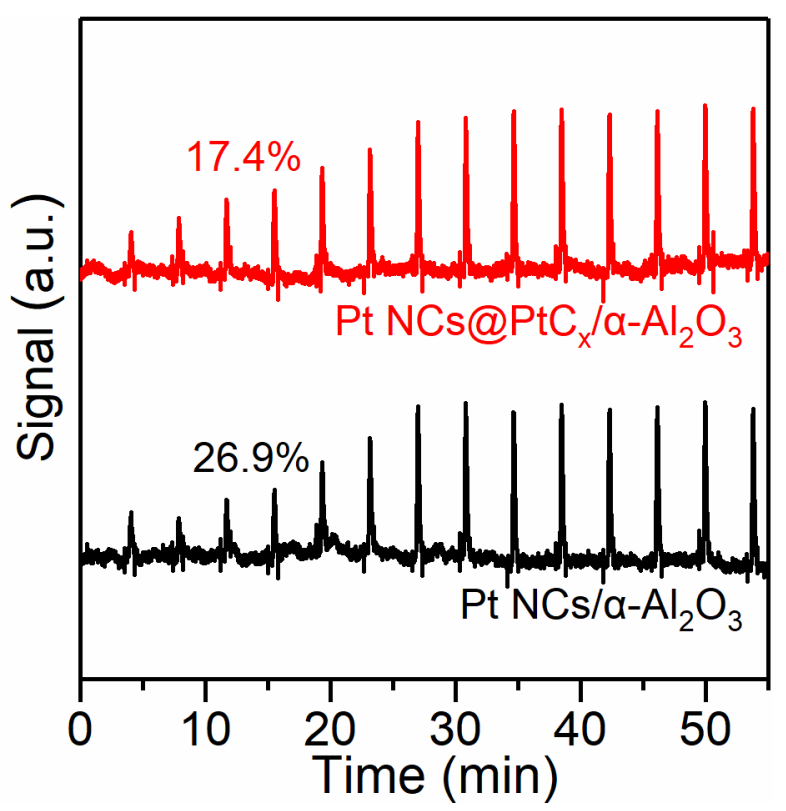

Figure S2. $\mathrm{CO}$ titration profiles of $\mathrm{Pt} \mathrm{NCs} / \alpha-\mathrm{Al}_{2} \mathrm{O}_{3}$ and $\mathrm{Pt} \mathrm{NCs} @ \mathrm{PtC}_{\mathrm{x}} / \alpha-\mathrm{Al}_{2} \mathrm{O}_{3}$. 


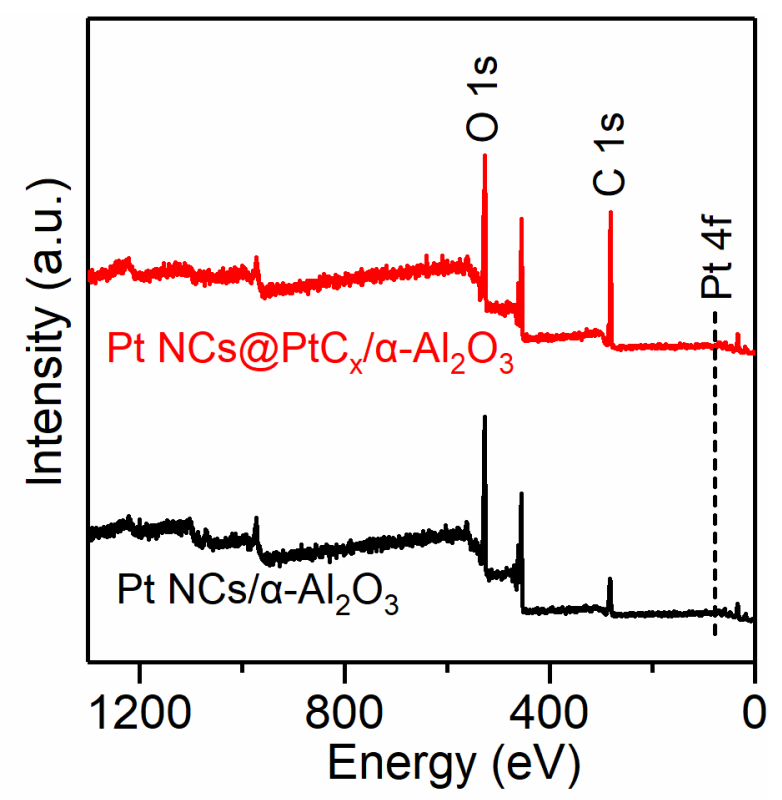

Figure S3. XPS spectrum of Pt $\mathrm{NCs} / \alpha-\mathrm{Al}_{2} \mathrm{O}_{3}$ and $\mathrm{Pt} \mathrm{NCs} @ \mathrm{PtC} \mathrm{C}_{\mathrm{x}} / \alpha-\mathrm{Al}_{2} \mathrm{O}_{3}$.

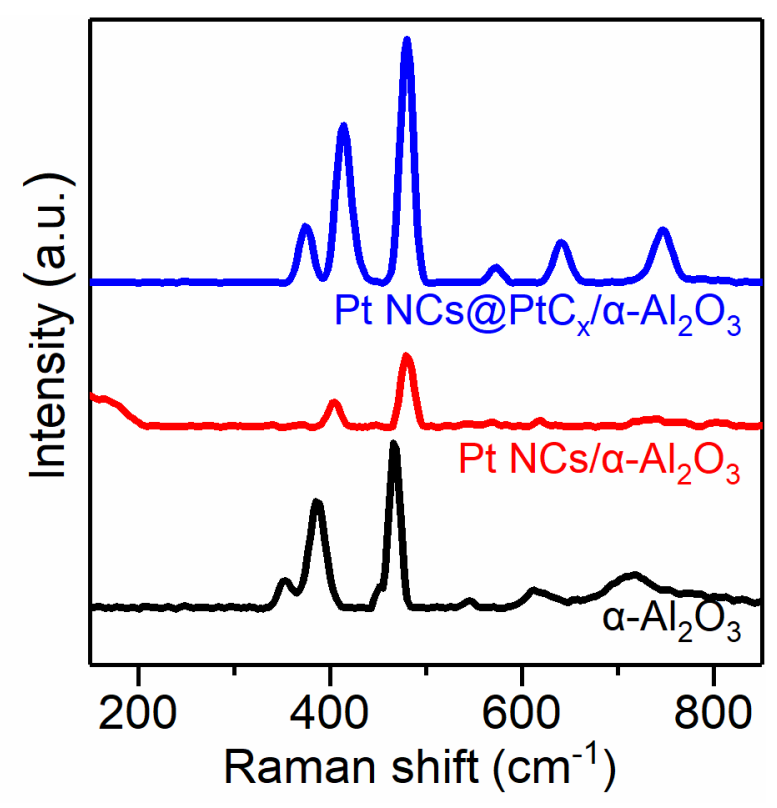

Figure S4. Raman spectra of $\alpha-\mathrm{Al}_{2} \mathrm{O}_{3}, \mathrm{Pt} \mathrm{NCs} / \alpha-\mathrm{Al}_{2} \mathrm{O}_{3}$ and $\mathrm{Pt} \mathrm{NCs} @ \mathrm{PtC}_{\mathrm{x}} / \alpha-\mathrm{Al}_{2} \mathrm{O}_{3}$. Due to the fluorescence of $\alpha-\mathrm{Al}_{2} \mathrm{O}_{3}$, a series of signals at $300-600 \mathrm{~cm}^{-1}$ were observed in the Raman spectra, which would overlap with the Pt-C bond signal in this range. 

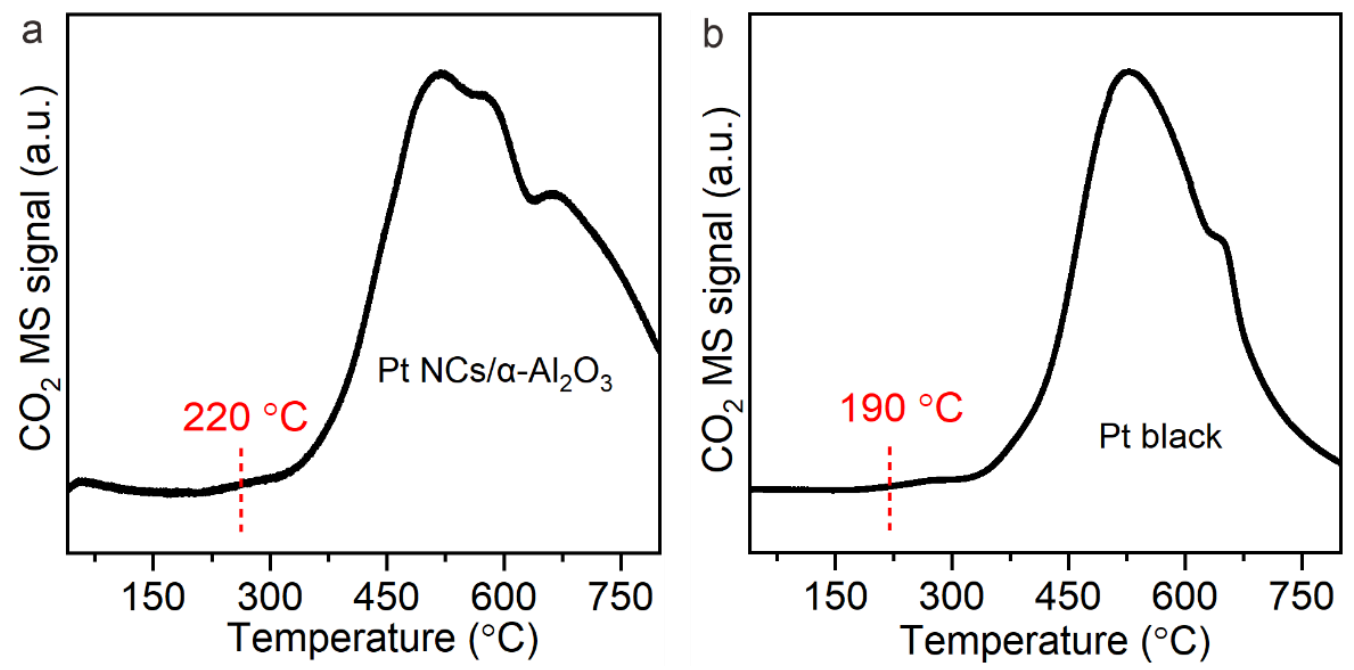

Figure S5. CO-TPR (mass spectrogram signal at m/e 44 of $\mathrm{CO}_{2}$ ) of (a) $\mathrm{Pt} \mathrm{NCs} / \alpha-\mathrm{Al}_{2} \mathrm{O}_{3}$ (b) Pt black.

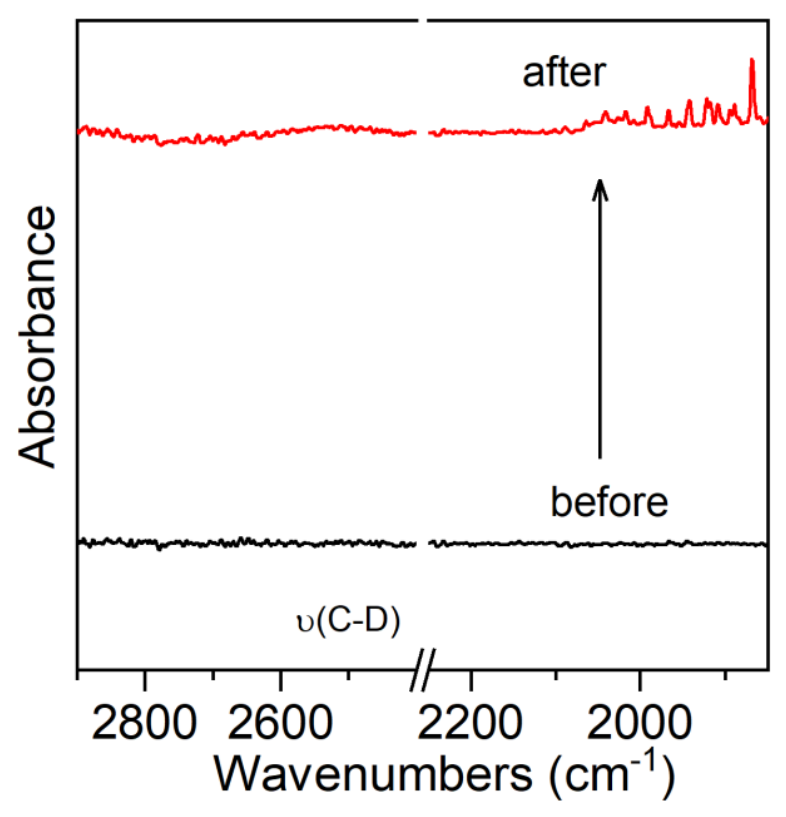

Figure S6. In situ DRIFTS of Pt $\mathrm{NCs} @ \mathrm{PtC}_{\mathrm{x}} / \alpha-\mathrm{Al}_{2} \mathrm{O}_{3}$ before and after treated under $\mathrm{D}_{2}$ atmosphere at $60{ }^{\circ} \mathrm{C}$. 


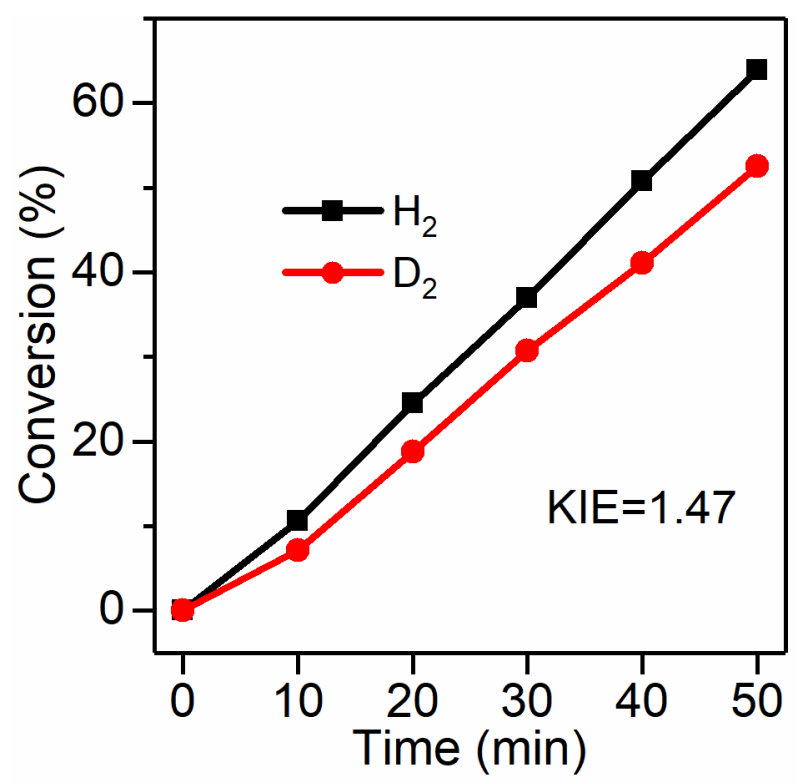

Figure S7. Kinetic isotope effect of $\mathrm{Pt} \mathrm{NCs} @ \mathrm{PtC}_{\mathrm{x}} / \alpha-\mathrm{Al}_{2} \mathrm{O}_{3}$ catalyzed $p$-CNB hydrogenation.

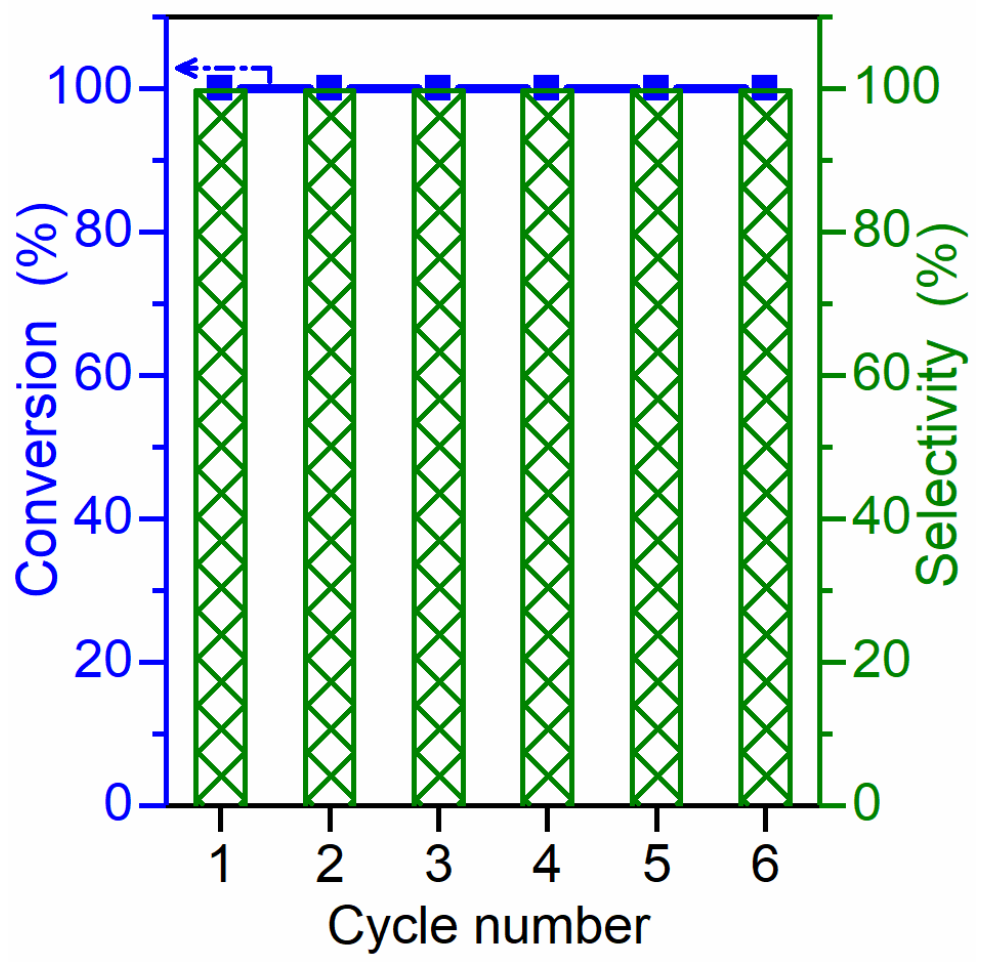

Figure S8. Catalytic stability of $p-\mathrm{CNB}$ of $\mathrm{Pt} \mathrm{NCs} @ \mathrm{PtC}_{\mathrm{x}} / \alpha-\mathrm{Al}_{2} \mathrm{O}_{3}$. 


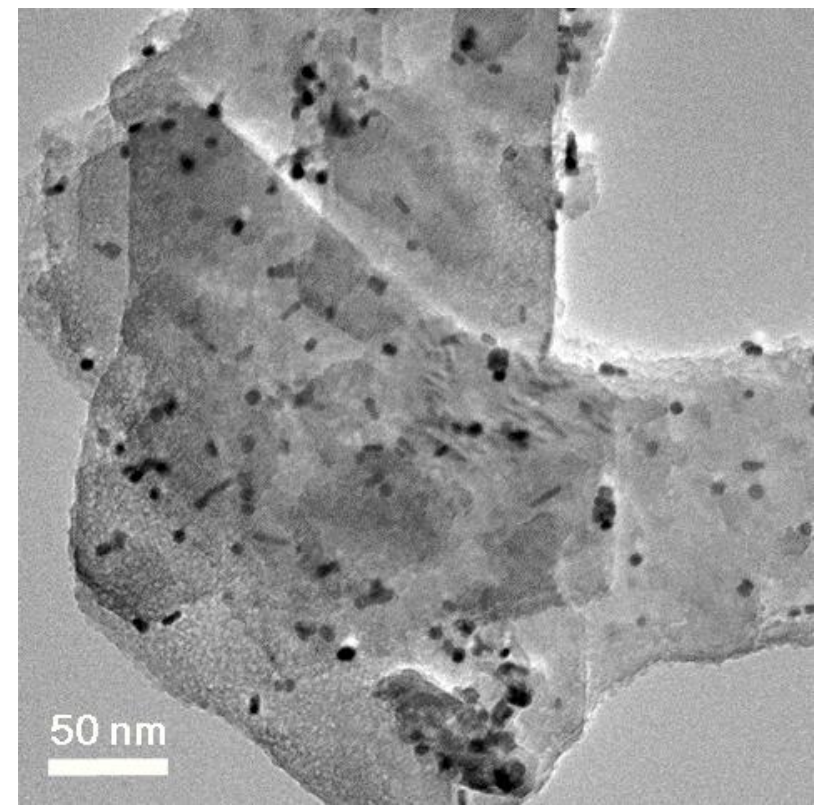

Figure S9. TEM image of $\mathrm{Pt} \mathrm{NCs} @ \mathrm{PtC}_{\mathrm{x}} / \alpha-\mathrm{Al}_{2} \mathrm{O}_{3}$ after six cycles of catalysis.

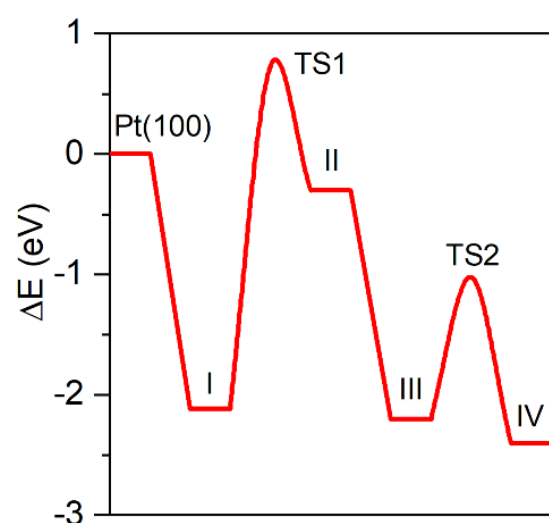

Reaction Coordinate

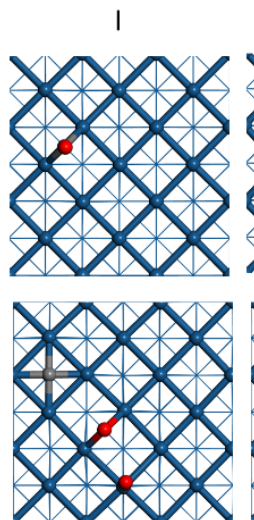

III
TS1
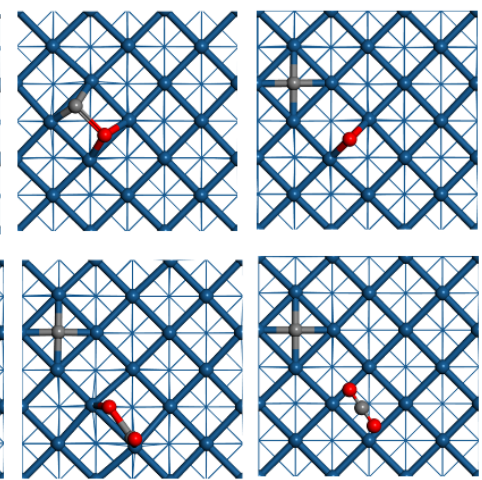

TS2

IV

Figure S10. The theoretical energy profile and corresponding structures related to the Boudouard reaction performed on Pt(100). I, CO adsorption; TS1, C-O cleavage; II, dissociated $\mathrm{C}$ and $\mathrm{O}$ on Pt surface; III, adsorption of second CO; TS2, reaction between surface $\mathrm{O}$ and the second $\mathrm{CO}$; IV, Pt surface with interstitial $\mathrm{C}$ and gas-phase $\mathrm{CO}_{2}$. Color code: blue, Pt; red, O; grey, C. 


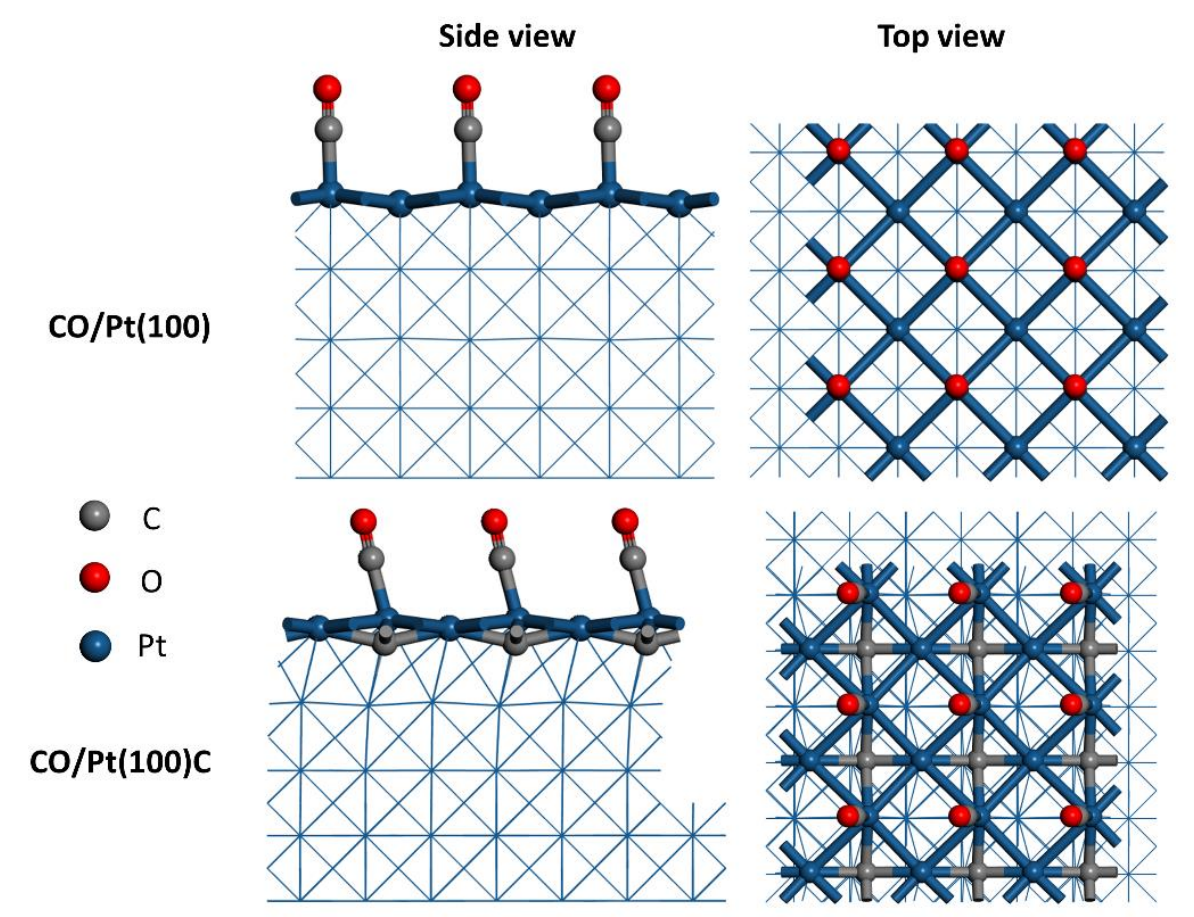

Figure S11. Top-view and side-view of the adsorbed CO on Pt (100) and $\mathrm{Pt}(100) \mathrm{C}$.

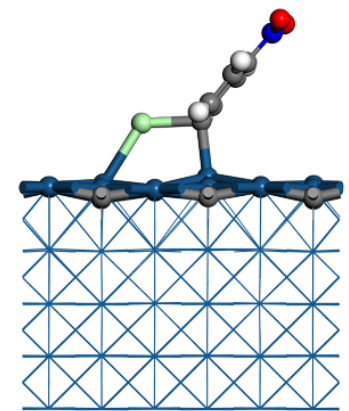

TS3

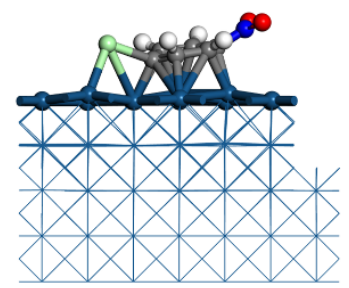

TS3'

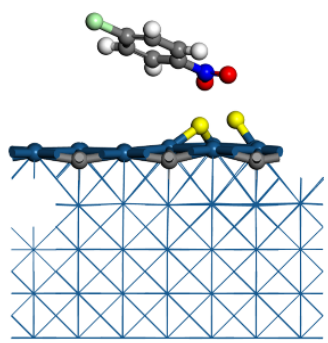

TS4

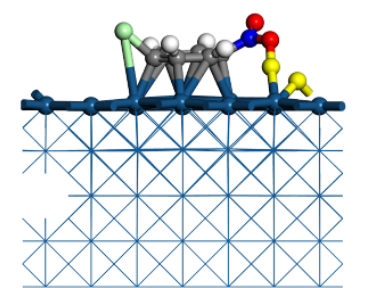

TS4'
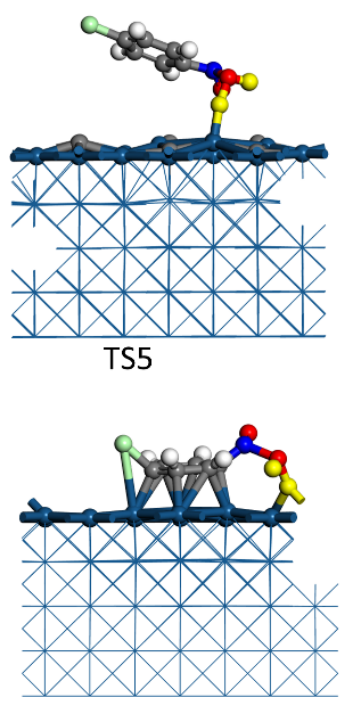

TS5'

$$
\odot_{\mathrm{Pt}} \odot_{\mathrm{C}} \odot_{\mathrm{O}} \odot_{\mathrm{N}} \mathrm{Cl}_{\mathrm{Cl}} \bigcirc_{\mathrm{H}} \mathrm{O}_{\mathrm{H}}
$$

Figure S12. Side-view of the transition state structures related to the $\mathrm{C}-\mathrm{Cl}$ bond dissociation and nitro group hydrogenation performed on $\mathrm{Pt}(100)$ and $\mathrm{Pt}(100) \mathrm{C}$. 


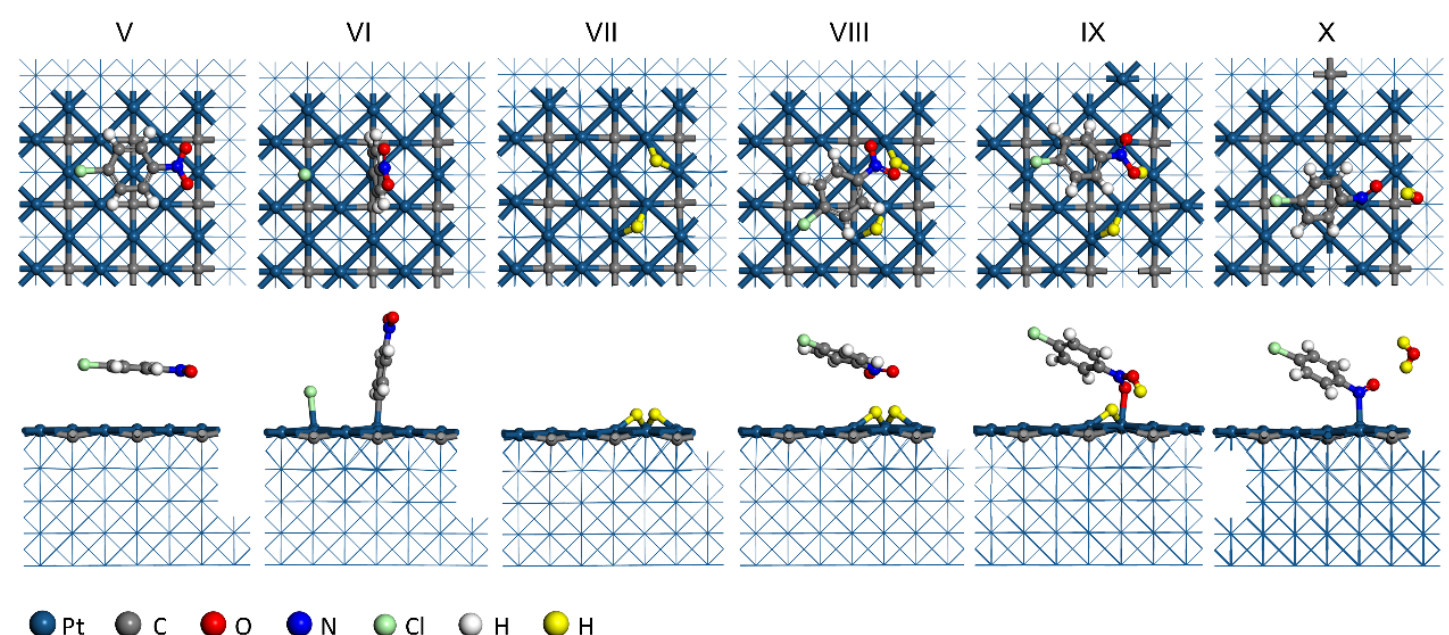

Figure S13. Top-view and side-view of the steady state structures related to the $\mathrm{C}-\mathrm{Cl}$ bond dissociation and nitro group hydrogenation performed on $\mathrm{Pt}(100) \mathrm{C}$.

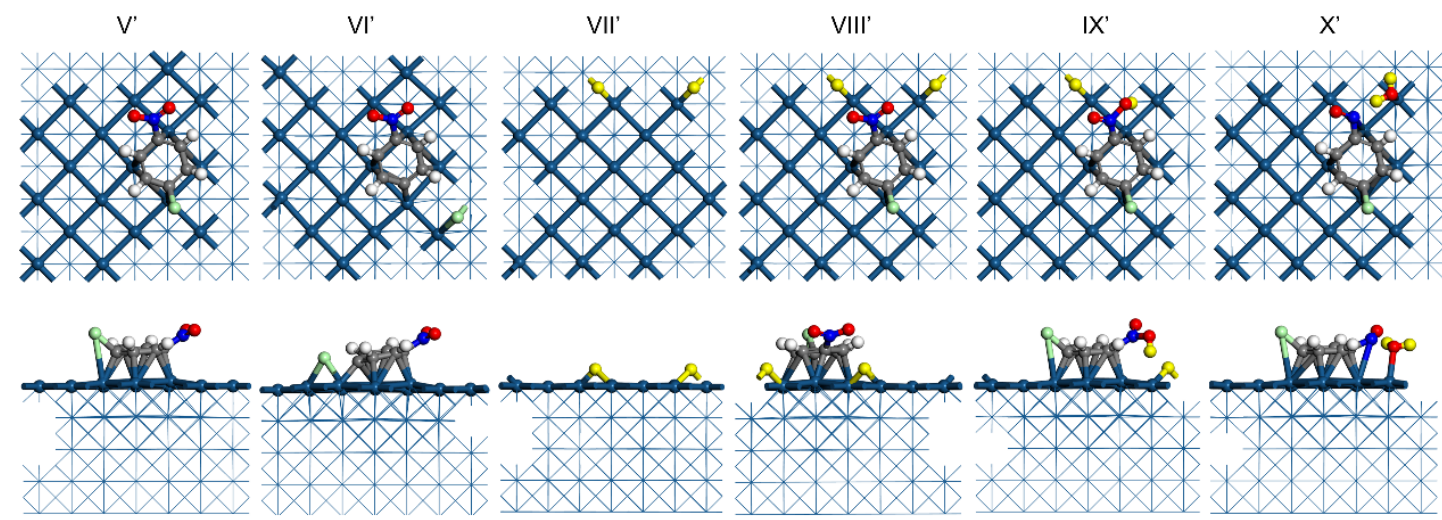

$\odot \mathrm{Pt} \odot \mathrm{C} \odot \mathrm{O} \odot \mathrm{N} \mathrm{OCl} \mathrm{OH} \mathrm{OH}$

Figure S14. Top-view and side-view of the steady state structures related to the C-Cl bond dissociation and nitro group hydrogenation performed on $\mathrm{Pt}(100)$. 


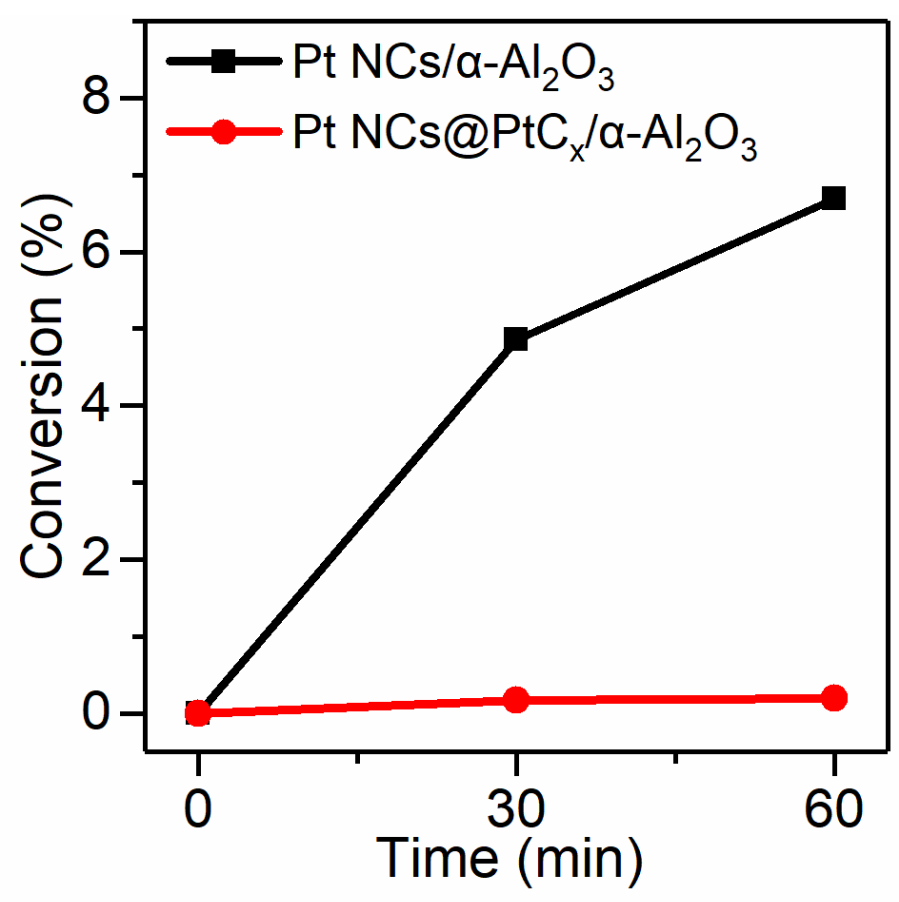

Figure S15. Catalytic hydrodechlorination of chlorobenzene with $\mathrm{Pt} \mathrm{NCs} / \alpha-\mathrm{Al}_{2} \mathrm{O}_{3}$ and $\mathrm{Pt} \mathrm{NCs} @ \mathrm{PtC}_{\mathrm{x}} / \alpha-\mathrm{Al}_{2} \mathrm{O}_{3}$.

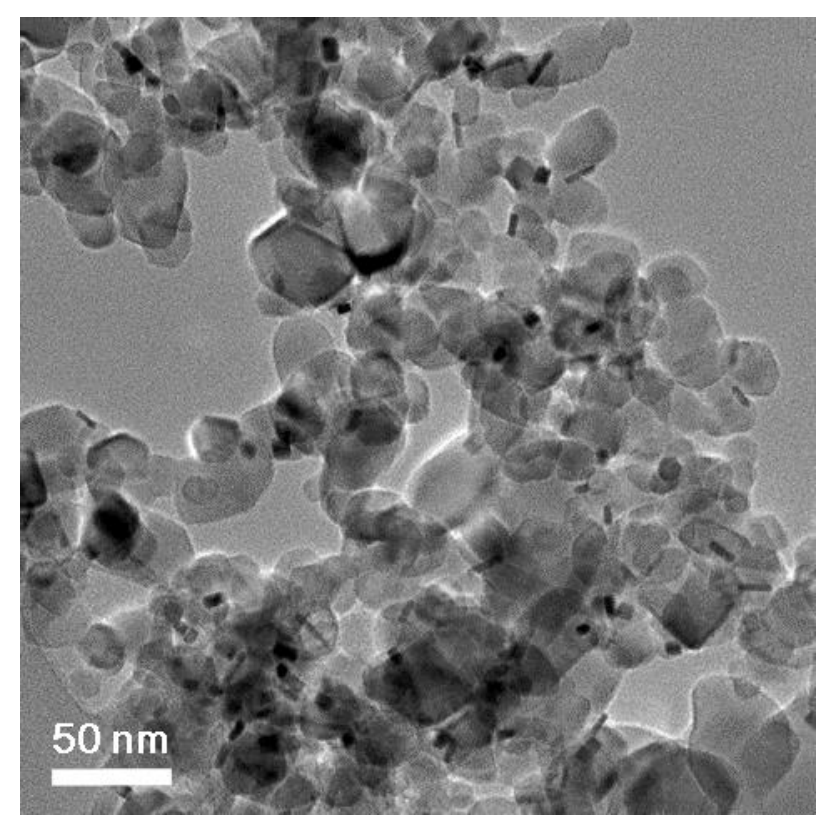

Figure S16. TEM image of $\mathrm{Pt} \mathrm{NCs} / \mathrm{TiO}_{2}$. 


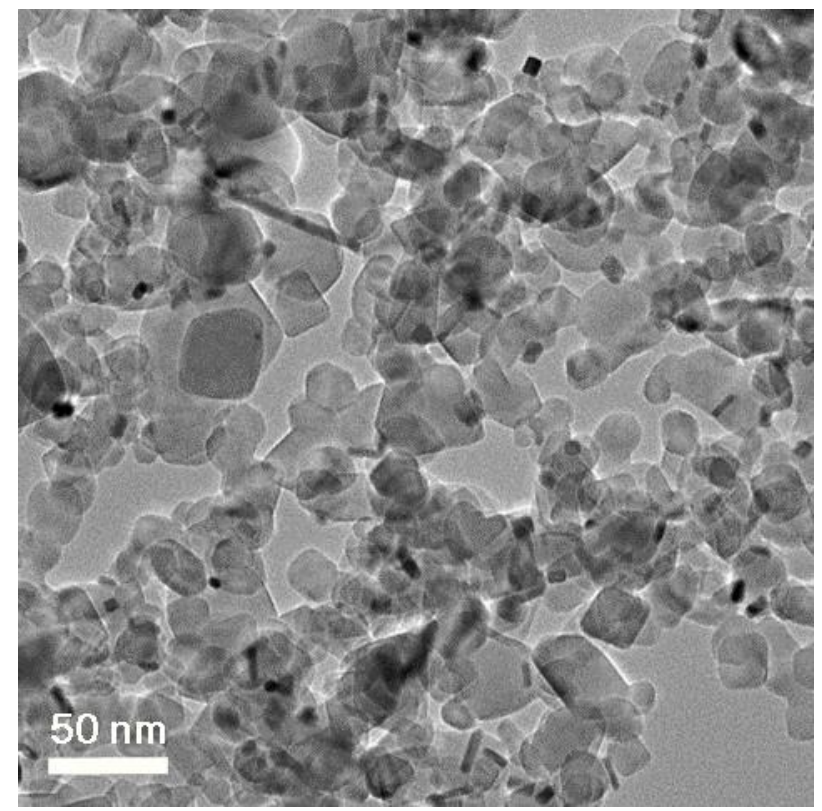

Figure S17. TEM image of Pt $\mathrm{NCs} @ \mathrm{PtC}_{\mathrm{x}} / \mathrm{TiO}_{2}$.

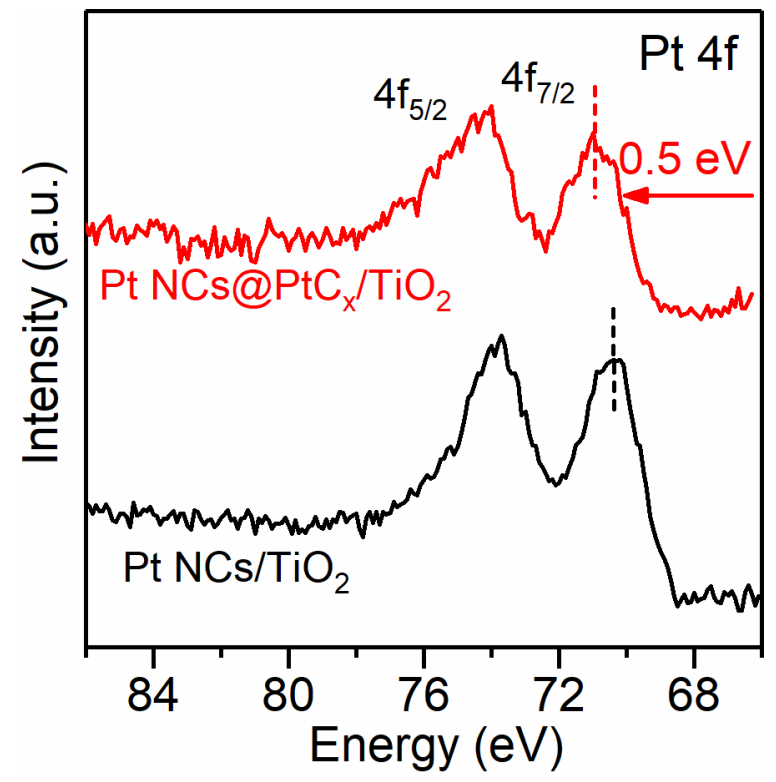

Figure S18. Pt 4f XPS of Pt NCs/TiO 2 and Pt NCs@ $@ \mathrm{PtC}_{\mathrm{x}} / \mathrm{TiO}_{2}$. 


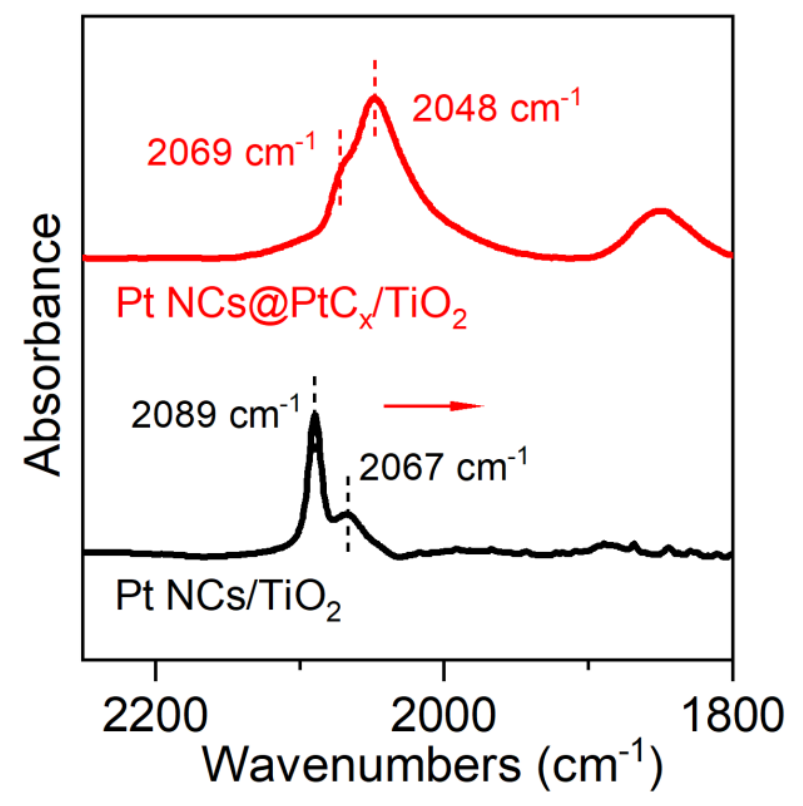

Figure S19. CO-DRIFTS of Pt NPs $/ \gamma-\mathrm{Al}_{2} \mathrm{O}_{3}$ and $\mathrm{Pt} \mathrm{NPs} @ \mathrm{PtC}_{\mathrm{x}} / \gamma-\mathrm{Al}_{2} \mathrm{O}_{3}$.

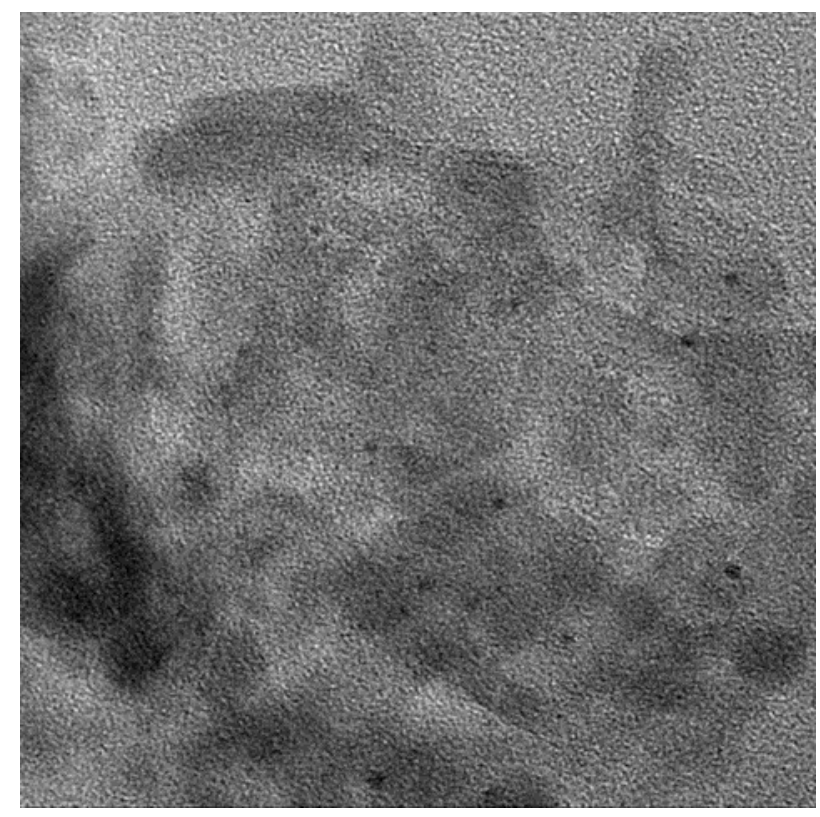

Figure S20. TEM image of $\mathrm{Pt} \mathrm{NPs} / \gamma-\mathrm{Al}_{2} \mathrm{O}_{3}$. 


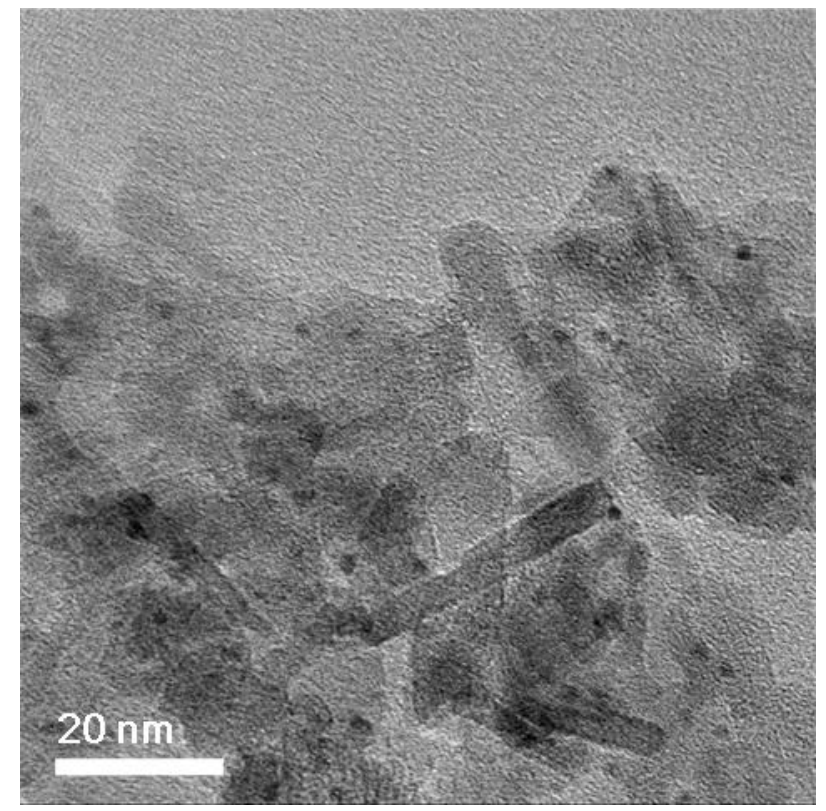

Figure S21. TEM image of Pt NPs@ $\mathrm{PtC}_{\mathrm{x}} / \gamma-\mathrm{Al}_{2} \mathrm{O}_{3}$.

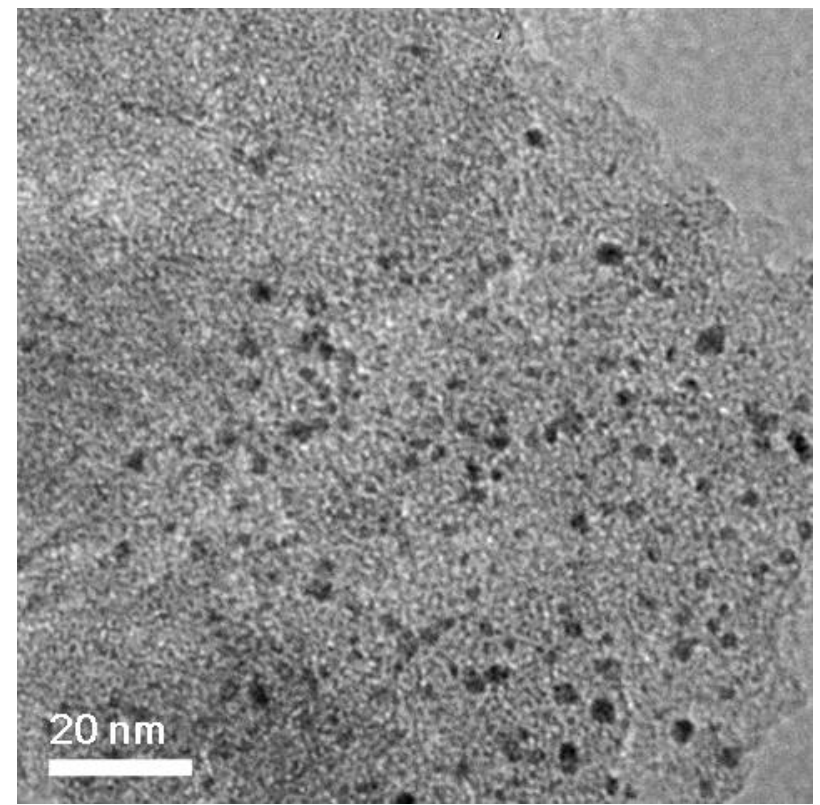

Figure S22. TEM image of commercial Pt/C. 


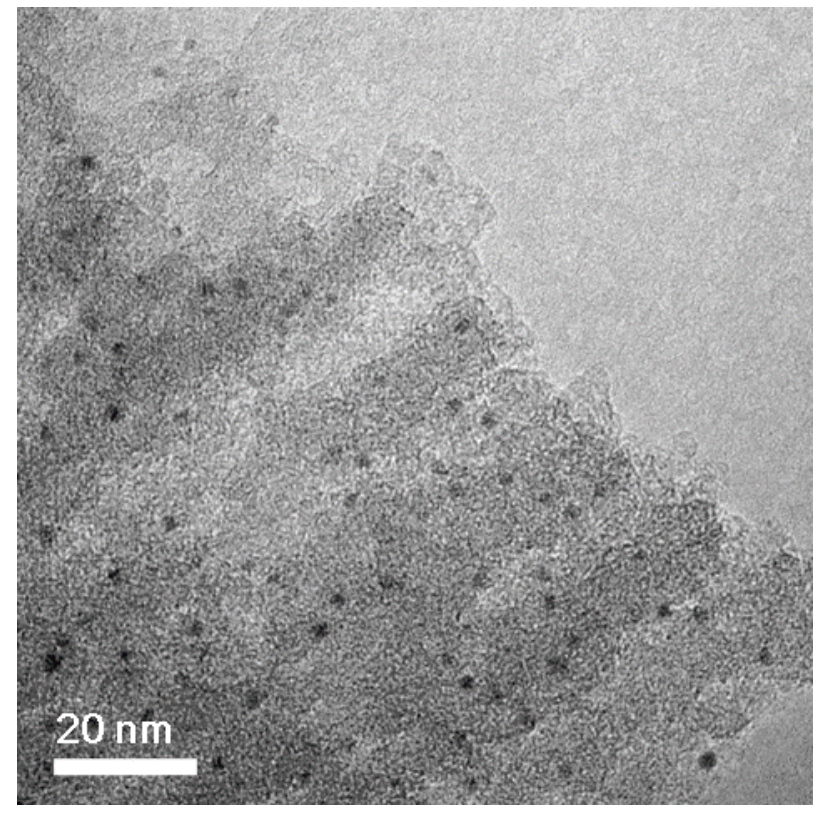

Figure S23. TEM image of commercial Pt@ $\mathrm{PtC}_{\mathrm{x}} / \mathrm{C}$. 